\title{
Twilight migrators: factors determining larval vertical distribution in Nephrops norvegicus with implications for larval retention
}

\author{
Ryan McGeady ${ }^{1,2}$, Colm Lordan ${ }^{2}$, Anne Marie Power ${ }^{1, *}$ \\ ${ }^{1}$ Ryan Institute, School of Natural Sciences, National University of Ireland Galway, H91 TK33 Galway, Ireland \\ ${ }^{2}$ Marine Institute, Rinville, Oranmore, H91 R673 Galway, Ireland
}

\begin{abstract}
The vertical distribution of pelagic marine larvae can greatly influence their dispersal due to depth-varying currents, which can determine larval retention or transport away from critical habitat. Vertical distribution of commercially important lobster Nephrops norvegicus larvae was examined over fishing grounds off the west and east coasts of Ireland. Larval vertical distribution for both grounds was significantly influenced by the temperature differential between the surface and $60 \mathrm{~m}$ depth, zooplankton biomass and, to a lesser extent, stratification, measured using the potential energy anomaly. Fixed station sampling was conducted over $3 \mathrm{~d}$ in the western Irish Sea (WIS) to investigate the occurrence and extent of a diel vertical migration (DVM). Larvae performed twilight DVM with an $\sim 10 \mathrm{~m}$ ascent prior to sunset and sunrise and a descent at midnight and after sunrise. Particle-tracking model simulations were used to examine the effect of DVM behaviour on larval retention over mud habitat. The presence of a DVM actually reduced the likelihood of retention on both the Aran and WIS grounds. Predicted larval retention was unusually low over the Aran grounds in 2018, which is potentially significant in the context of historic stock fluctuations in this area. These findings suggest that understanding larval dynamics could be crucial in managing $N$. norvegicus stocks on fishing grounds, in particular those with variable interannual oceanography and a low rate of larval donation from other grounds.
\end{abstract}

KEY WORDS: Vertical distribution $\cdot$ Diel vertical migration $\cdot$ Larvae $\cdot$ Particle tracking $\cdot$ Larval retention $\cdot$ Nephrops norvegicus

\section{INTRODUCTION}

Nephrops norvegicus (Norway lobster) is a benthic crustacean found in the northeastern Atlantic and the Mediterranean Sea. Adults are restricted to mud habitats, where they construct and reside in burrows. Like many other decapod crustaceans, after embryo hatching, $N$. norvegicus undergo a pelagic larval phase prior to settlement and eventual recruitment into the adult population. Free-swimming larvae pass through 3 stages by a series of moults prior to rejoining the benthic phase as postlarvae (Farmer 1974).

\footnotetext{
${ }^{*}$ Corresponding author: annemarie.power@nuigalway.ie
}

Both embryonic development and larval development are dependent on temperature. Therefore, the duration of embryo incubation, timing of larval hatching and larval duration vary with latitude (Sardà 1995, Dickey-Collas et al. 2000). In warmer waters of the Mediterranean Sea, the duration of embryo incubation can last between 120 and $180 \mathrm{~d}$ (Relini et al. 1998). In contrast, populations situated off Iceland that experience cooler temperatures incubate for longer periods, 380 d (Eiriksson 1970). Efforts to describe the relationship between temperature and larval development have been met with limited success due to the difficulties of captive rear-

() The authors 2019. Open Access under Creative Commons by Attribution Licence. Use, distribution and reproduction are unrestricted. Authors and original publication must be credited. 
ing to postlarval stage. Observed developmental rates of Stage I and II larvae (combined) range from $33 \mathrm{~d}$ at $9^{\circ} \mathrm{C}$ to $13 \mathrm{~d}$ at $15^{\circ} \mathrm{C}$ (Thompson \& Ayers 1989, Dickey-Collas et al. 2000). However, the larval period is further prolonged when the duration of Stage III is accounted for. On the western Irish Sea (WIS) grounds, larvae are present in the water column between March and June with peak densities in May (Nichols et al. 1987). Larvae appear earlier off the west coast in a small population in Galway Bay, where the larval season lasts from February to May with a peak from March to April (de Bhaldraithe 1976). However, the seasonality of larval timing at the much larger population on the Aran grounds (Fig. 1) was unknown until now.

$N$. norvegicus fisheries are among the most economically valuable in Europe (Ungfors et al. 2013). Landings from Irish waters in 2017 had a value of
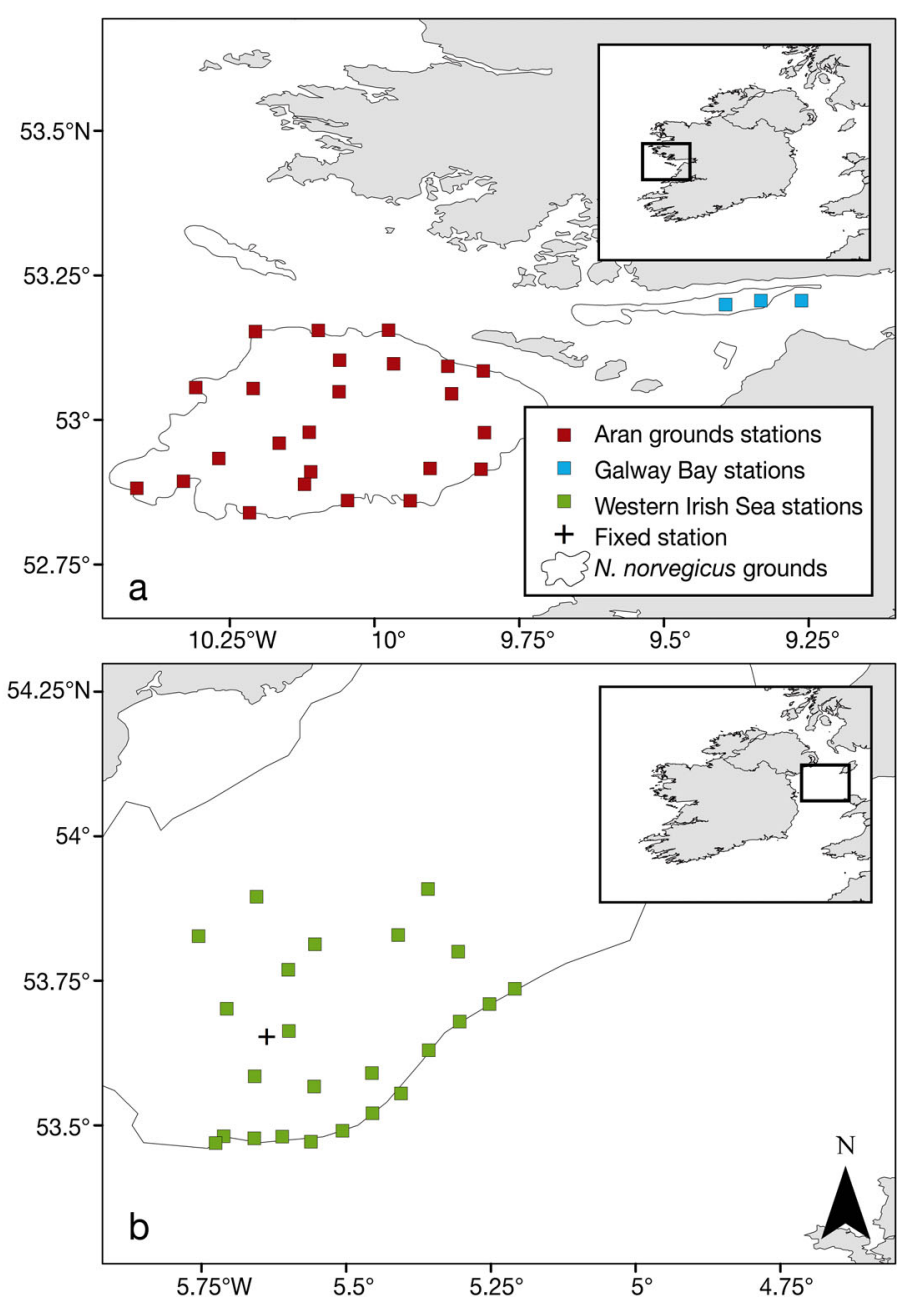

Fig. 1. Sampling stations on the (a) Aran and Galway Bay grounds and (b) western Irish Sea grounds. Outline of Nephrops norvegicus mud patches are also indicated
$€ 54$ million at first sale (Doyle et al. 2018a). Underwater television (UWTV) is used as a method of estimating stock size by calculating burrow density. The UWTV surveys are well established in Ireland, and surveys have been conducted annually for $17 \mathrm{yr}$ on the Aran grounds and for $16 \mathrm{yr}$ in the WIS. Observed burrow densities have remained relatively stable over time at the densely populated WIS grounds (Clements et al. 2018). However, the Aran and Porcupine Bank grounds, off Ireland's west coast, have experienced marked fluctuations, making the sustainability of the respective fisheries a concern (Doyle et al. 2018a,b).

A number of factors such as recruitment, exploitation, predation or other sources of natural mortality determine $N$. norvegicus population size (Johnson et al. 2013). It is thought that local oceanographic conditions can play a significant role in the recruitment success of this species because of the potential for larvae to be transported beyond the boundary of critical mud habitats, which can be patchy and spatially isolated (Bell et al. 2006). In certain instances, localised oceanographic features can aid in larval retention, such as a seasonal gyre that coincides with the larval season in the WIS, which is suggested to entrain larvae over the WIS mud patch (Hill et al. 1996, Olbert et al. 2012). However, off the west coast of Ireland, where stock size is more likely to fluctuate, no obvious retention mechanism exists (O'Sullivan et al. 2015).

Weak swimming capabilities prevent $N$. norvegicus larvae from counteracting the force of horizontal currents; however, larvae can have more influence over their vertical position in the water column. Because currents vary with depth, larvae may ultimately control horizontal dispersal by regulating vertical distribution (Queiroga \& Blanton 2005). Vertical position also has major consequences for feeding and predation exposure (Huntley \& Brooks 1982, Bollens $\&$ Frost 1989). Many factors are known to influence the vertical distribution of pelagic decapod larvae such as light, pressure, temperature, salinity, currents and endogenous rhythms (Roberts 1971, Hughes 1972, Ennis 1975, 1986, Kelly et al. 1982, Forward 1987). Diel vertical migration (DVM) is widespread among decapod larvae, with predator evasion thought to be one of the main reasons for the behaviour (Hays 2003, Queiroga \& Blanton 2005, dos Santos et al. 2008). Three main types of DVM are known to exist: nocturnal DVM, when an ascent to shallower depths occurs between dusk and dawn; reverse DVM, when ascent occurs during the day; and twilight DVM, when 2 ascents and descents are performed in a $24 \mathrm{~h}$ 
period, i.e. a first ascent at dusk, followed by a descent at midnight and then a second ascent to the surface before a descent after sunrise (Forward 1988).

Several modelling studies have highlighted the importance of vertical distribution to horizontal dispersal by examining distinct migratory behaviours (Emsley et al. 2005, Marta-Almeida et al. 2006, 2008). A downward migration and overall deeper vertical distribution was favourable to settlement and retention of coral reef fish larvae in the Straits of Florida (Huebert et al. 2011). Similarly, migrating copepods exposed to near-bottom onshore flow during the day had a greater likelihood of retention than those at the surface (Batchelder et al. 2002). Meanwhile, Phelps et al. (2015) examined the retentive properties of the WIS gyre and concluded that retention was maximised when $N$. norvegicus larvae remained at the depth of peak gyral flow; however, retention was less likely when DVM behaviour was introduced. If thermoclines are present, larvae in warmer waters above the thermocline develop faster and settle earlier, and less time spent in the pelagic larval phase is linked to shorter dispersal distances for near-surface meroplankton (Shanks 2009). Thus, to fully comprehend the horizontal advection of planktonic larvae, an understanding of vertical distribution is essential.

Few studies have examined the vertical distribution of $N$. norvegicus larvae in great detail. Peak densities of larvae have been observed in the upper $40 \mathrm{~m}$ of the water column (Hillis 1974, Smith 1987, Lindley et al. 1994). A small ascent was observed from daytime to dusk, suggesting the possible occurrence of a DVM (Hillis 1974). In addition, Lindley et al. (1994) observed a shallower distribution during the spring bloom in April compared to afterwards in May. However, in most cases, information on this subject has been indirect, with many studies primarily focused on horizontal distribution, or collecting samples at insufficiently high temporal resolution, or not obtaining adequate numbers of larvae to thoroughly examine DVM. As a result, little is known about the environmental drivers that influence vertical distribution or their relative influence in this species.

The principal aims of the present study were to (1) provide the first information on larval seasonality on the Aran grounds off the west coast of Ireland, (2) explore biotic and abiotic factors that influence vertical distribution, (3) investigate the potential occurrence and extent of DVM behaviour in $N$. norvegicus larvae and (4) determine the effect of DVM behaviour on larval transport and retention.

\section{MATERIALS AND METHODS}

\subsection{Sample collection}

Larvae were sampled at 2 grounds from 4 to 15 April 2018 onboard the RV 'Celtic Voyager'. At the Aran grounds, situated off the west coast of Ireland, sampling was conducted at 24 stratified random stations chosen using a randomisation process, whereby 12 randomly generated stations were allocated on the outer boundary of the Nephrops norvegicus mud patch, and 12 stations were chosen towards the centre of these grounds (Fig. 1). During the second day of sampling on the Aran grounds, work was discontinued due to poor weather, and 3 opportunistic stations were sampled on the Galway Bay grounds before continuing on the Aran grounds. After a $48 \mathrm{~h}$ transit period to the east coast, sampling continued on the WIS grounds, from 9 to 15 April, with a further 24 stratified random stations sampled. Again, 12 of the stations were on the boundary and 12 were situated towards the centre of the WIS grounds.

In addition to the sampling conducted above, fixed station sampling was performed during 3 consecutive days on the WIS grounds in an area with historically high densities of $N$. norvegicus larvae in April (http://data.cefas.co.uk/\#/View/2620, accessed 13 December 2016). At the fixed station, zooplankton samples were collected every $3 \mathrm{~h}$ (00:00, 03:00, 06:00, 09:00, 12:00, 15:00, 18:00 and 21:00 $h_{\text {i }}$ UTC + 1). Fixed station sampling commenced precisely at the indicated hour to ensure sampling times were identical across 3 diel cycles. In total, 24 sampling events were completed over $69 \mathrm{~h}$. Zooplankton samples were collected using a multinet (Hydrobios type Midi, $0.25 \mathrm{~cm}^{2}$ aperture size, $300 \mu \mathrm{m}$ mesh size). All of the following depth strata were sampled: $10 \mathrm{~m}$ from bottom to $40 \mathrm{~m}, 40-30 \mathrm{~m}, 30-20 \mathrm{~m}, 20-10 \mathrm{~m}$ and $10-0 \mathrm{~m}$. Increased sampling intensity took place in surface layers due to evidence that $N$. norvegicus larvae are concentrated in the upper $40 \mathrm{~m}$ of the water column (Hillis 1974, Smith 1987, Lindley et al. 1994). To ensure that adequate numbers of larvae were caught in each depth stratum, a minimum seawater volume of $100 \mathrm{~m}^{-3}$ was filtered. The plankton sampler was deployed on an oblique haul, and speed was carefully controlled to ensure equal sampling of each depth stratum. Once aboard, samples were retrieved and preserved in buffered $4 \%$ formaldehyde solution for processing in the laboratory. For each sample, larvae were counted and sorted according to larval stage. Zooplankton biomass $\left(\mathrm{ml} \mathrm{m}^{-3}\right)$ associated with each sample was measured using the volume dis- 
placement method (Beers 1976). Before measuring the displacement volume, zooplankton samples were filtered and blotted for a minimum of $5 \mathrm{~min}$ to remove excess interstitial water, and zooplankton measuring $>3 \mathrm{~cm}$ were removed to avoid bias associated with large individual organisms.

Vertical profiles of temperature were measured from the surface of the water column to within $10 \mathrm{~m}$ of the seabed using a multinet-mounted CTD. Profiles of salinity, density and fluorescence were collected using a Seabird SBE 911 CTD with mounted ECO FLNTU fluorometer. To examine the association between water column characteristics and larval vertical distribution, the difference between the surface and $60 \mathrm{~m}$ was calculated for temperature and salinity at every station, termed $\Delta$ Temperature and $\Delta$ Salinity, respectively.

The potential energy anomaly $\left(\mathrm{PEA}_{i} \mathrm{~J} \mathrm{~m}^{-3}\right.$ ) was calculated for each station to provide a measure of stratification of the water column. The PEA is defined as the amount of energy needed to fully homogenise the water column, described according to Simpson et al. (1977) by the equation:

$$
\mathrm{PEA}=\frac{1}{D} \int_{-H}^{n} g z(\bar{p}-p) \mathrm{d} z
$$

where $g$ is the gravitational acceleration, $z$ is the vertical coordinate from $-H$ (deepest measurement) up to the sea surface $n$ and $p(z)$ is the density profile in a water column of depth $D$.

A hyperspectral irradiance sensor (Trios Ramses $\mathrm{ACC}_{i} 0.3 \mathrm{~nm}$ spectral accuracy) was deployed prior to collection of zooplankton samples to measure underwater downwelling irradiance $\left(\mathrm{mW} \mathrm{m}^{-2} \mathrm{~nm}^{-1}\right)$ in the upper $40 \mathrm{~m}$ of the water column. The sensor had a wavelength range between 320 and $950 \mathrm{~nm}$ and logged 1 measurement $\mathrm{s}^{-1}$. Tidal height data were extracted from the Irish National Gauge Network (data. marine.ie/geonetwork/srv/eng/catalog.search\#/ metadata/ie.marine.data:dataset.2774, accessed 15 January 2019). Tidal data were taken from the Inishmore gauge for stations on the Aran grounds and from the Port Oriel gauge for the WIS grounds.

The weighted mean depth (WMD) of $N$. norvegicus larvae was calculated for all stations as follows:

$$
\mathrm{WMD}=\frac{\sum_{i=1}^{5} n_{i} d_{i}}{\sum_{i=1}^{5} n_{i}}
$$

where $n_{i}$ is the no. of ind. per $\mathrm{m}^{-3}$ of larvae at the $i^{\text {th }}$ stratum and $d_{i}$ is the mean depth of the $i^{\text {th }}$ stratum. WMD provides a single measure of depth, integrated across depth strata at a particular station, i.e. at the fixed station in the current study, 1 WMD value rep- resents the average vertical distribution of $N$. norvegicus larvae across all 5 strata at a particular time of day. This value enables different times of day to be compared. WMDs were also used to allow comparisons across sampling stations to investigate horizontal patterns of preferred larval depth. When the total number of larvae was $<10$ individuals, stations were excluded from analyses. The WMD metric was also used to determine the average depth of zooplankton biomass per station.

\subsection{Analysis}

Larval densities were compared between grounds for each larval stage using Mann-Whitney $U$-tests. Comparisons between stages within grounds and day-night larval densities were made using Wilcoxon signed rank tests. These tests were chosen due to non-normality of data after transformation.

To examine the association between biotic-abiotic factors and WMD of Stage I larvae as a response variable, a multiple linear regression was performed across horizontally sampled stations on the Aran and WIS grounds. Stage I larvae were used in these analyses due to their relatively high densities in comparison to later larval stages. The initial maximal model included the following variables: average zooplankton biomass (across 5 depth strata), WMD of zooplankton biomass, depth of maximum fluorescence, tidal height, bottom depth, PEA, $\Delta$ Temperature (surface temperature - temperature at $60 \mathrm{~m}$ ), $\Delta$ Salinity, irradiance at $15 \mathrm{~m}$, time of day and location of grounds (Aran or WIS). Prior to running analyses, correlations between explanatory variables were examined by obtaining variance inflation factors (VIFs). When a VIF of $>3$ was observed, one of the correlated variables was excluded from the analysis. A correlation between PEA and $\triangle$ Salinity was detected, and the latter was removed. A model simplification process was followed using a stepwise forward selection of variables. The optimal model was identified using Akaike's information criterion (AIC); when the addition of further variables did not bring a reduction in AIC, the model was considered optimal. The AIC method allows the user to fit the optimal model by balancing complexity in contrast to goodness of fit (Akaike 1974). Predictive performance of the final model was evaluated using leave-one-out cross-validation. Leave-one-out cross-validation fits the model using all but 1 observation in the dataset and is then repeated for all observations (Efron 1983, Jain et al. 1987). To evaluate model performance, 
predicted versus observed values from the leaveone-out procedure were compared using Spearman's rank correlation.

To examine the relative importance of each predictor in the optimal model, the respective amount of explained variance was assessed. The metric lmg in the $\mathrm{R}$ package relaimpo was used to decompose the overall $\mathrm{r}^{2}$ into non-negative contributions for each predictor that sum to the total $\mathrm{r}^{2}$ (Johnson \& LeBreton 2004, Grömping 2006)

To investigate the occurrence of a DVM, the effect of time of day on WMD of Stage I larvae was examined across 3 daily cycles $(69 \mathrm{~h})$ at the fixed station, using ANOVA with Tukey's HSD post hoc tests. In addition, a simple linear regression was used to examine the association between downwelling irradiance at $15 \mathrm{~m}$ during daylight hours and Stage I larval WMD. All analyses were performed using the statistical software R version 3.5.1 (R Core Team 2018).

\subsection{Particle tracking}

To investigate the effect of DVM on larval retention and advection distance, particle-tracking model simulations were carried out using a 3D hydrodynamic model. Output from the Regional Ocean Modelling System (ROMS) was used to replicate hydrography around Ireland. The ROMS model is a free-surface hydrostatic primitive equations model that uses orthogonal curvilinear coordinates on an Arakawa $\mathrm{C}$-grid for the horizontal dimension and a prognostic terrain-following coordinate for the vertical dimension (Shchepetkin \& McWilliams 2005). A ROMS model encompassing a large area of the northwestern European continental shelf including Irish territorial waters was used (i.e. NE_Atlantic model, Dabrowski et al. 2016). The model has a resolution of 1.1 to $1.6 \mathrm{~km}$ in Irish coastal waters and has 40 terrain-following vertical layers (Dabrowski et al. 2016). Hourly current velocity output produced by the ROMS model was used in particle tracking.

Model output from ROMS for the relevant period in 2018 was coupled with a 3D individual-based model (Ichthyop v3; Lett et al. 2008) to simulate larval transport originating from the Aran and WIS grounds. Particle-tracking simulations were conducted using hourly ROMS current output using a Runge-Kutta $4^{\text {th }}$ order numerical scheme and a 5 min time step. In total, 10000 particles were released on each ground for each of the scenarios, and particles were released with a uniform spatial distribution across the respective grounds. The simulation began on 15 March for the Aran grounds and 1 April for the WIS grounds to reflect the predicted timing of larval hatching from observed larval stages and densities (see Section 3.1). Simulation duration was set at $60 \mathrm{~d}$, which was in close agreement with larval durations estimated from regression parameters obtained from previous experiments of temperature-dependent development (Smith 1987, Thompson \& Ayers 1989, DickeyCollas et al. 2000) combined with $60 \mathrm{~d}$ average sea surface temperature from the ROMS model on the Aran grounds $\left(64 \mathrm{~d}\right.$ at $8.8^{\circ} \mathrm{C}$ ) and WIS grounds (62 $\mathrm{d}$ at $9^{\circ} \mathrm{C}$ ). Three DVM behaviour scenarios were simulated for both grounds: (1) no DVM, (2) twilight DVM and (3) nocturnal DVM. In the no DVM scenario, particles remained fixed at a depth of $30 \mathrm{~m}$ for the Aran grounds and $20 \mathrm{~m}$ for the WIS throughout the simulation, in line with observations of average larval WMD from empirical data in the present study. Twilight DVM particles made 2 ascents and descents over a $24 \mathrm{~h}$ period, an ascent at dusk followed by a descent at midnight and another ascent before a daytime descent. Nocturnal DVM particles were programmed to make 1 ascent at dusk and 1 descent at dawn over the diel cycle. For the twilight DVM and nocturnal DVM scenarios, particles ascended and descended between 15 and $30 \mathrm{~m}$ for the Aran grounds and 10 and $20 \mathrm{~m}$ for the WIS to reflect empirical observations of WMD. The percentage of particles within the boundaries of the grounds in which they originated (particle retention) and straight line distance from initial to final position after $60 \mathrm{~d}$ were calculated for each of the 3 scenarios on each ground.

\section{RESULTS}

\subsection{Horizontal distribution of larvae}

Average densities of Stage I Nephrops norvegicus larvae on the Aran grounds were $0.14 \pm 0.09$ ind. $\mathrm{m}^{-3}$ (mean $\pm \mathrm{SD}$ ), with lowest densities observed to the western and northeastern boundaries (Fig. 2a). Stage I larvae were significantly more abundant than Stage II larvae $\left(0.03 \pm 0.03\right.$ ind. $\left.\mathrm{m}^{-3}\right)$ on the Aran grounds (Wilcoxon signed rank test, $\mathrm{n}_{1}=\mathrm{n}_{2}=24, Z=-4.1$, $\mathrm{p}<$ 0.001), and maximum Stage II densities were observed to the south of the grounds (Fig. 2b). Stage I $\left(0.04 \pm 0.02\right.$ ind. $\left.\mathrm{m}^{-3}\right)$, II $\left(0.05 \pm 0.05\right.$ ind. $\left.\mathrm{m}^{-3}\right)$ and III $\left(0.02 \pm 0.01\right.$ ind. $\left.\mathrm{m}^{-3}\right)$ larvae were observed at each of the 3 stations on the Galway Bay grounds. The presence of Stage III larvae indicated that seasonality was further advanced in this coastal area compared to the nearby Aran grounds. 


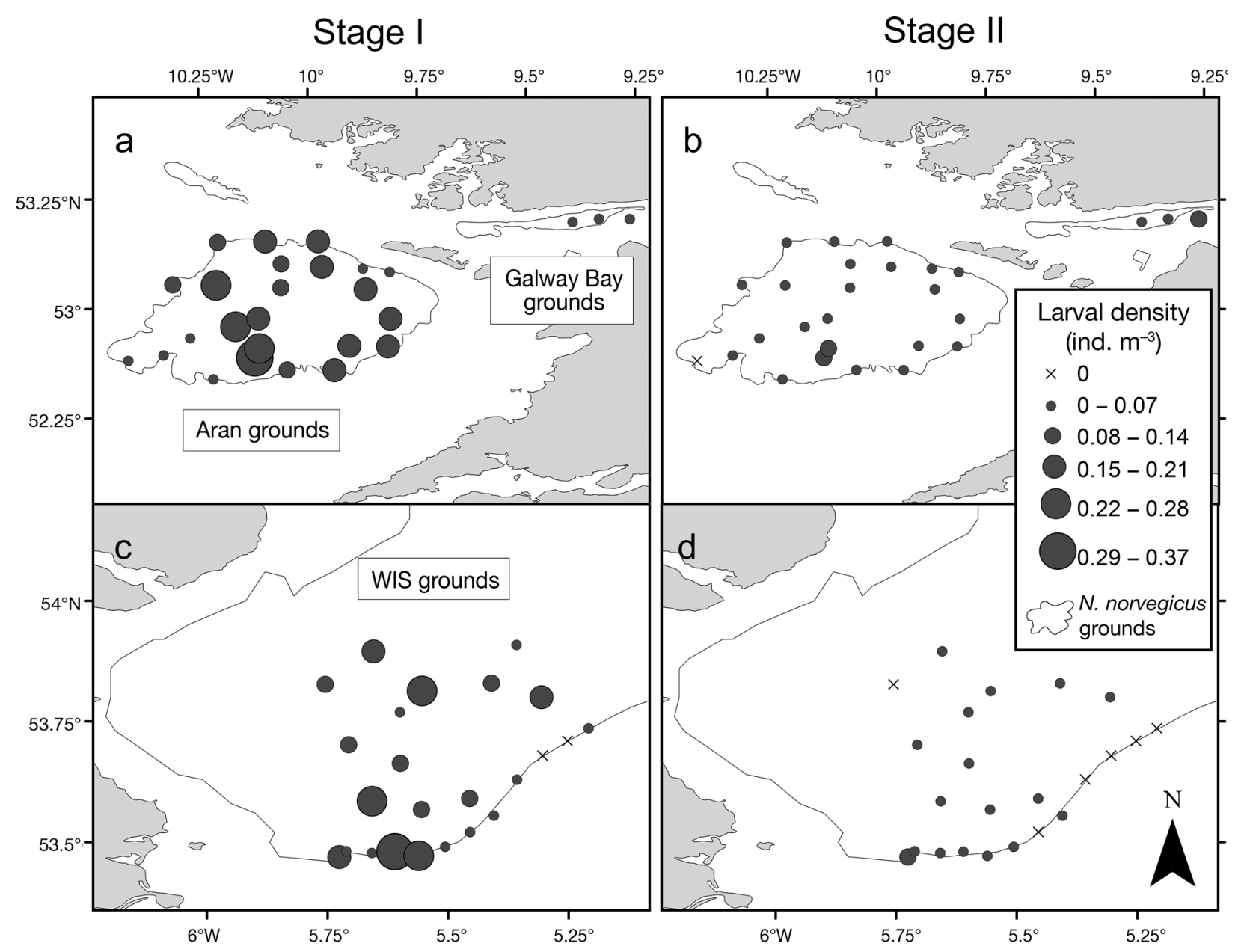

Fig. 2. Densities (ind. $\mathrm{m}^{-3}$ ) of Stage I and II Nephrops norvegicus larvae on the (a,b) Aran and Galway Bay grounds and (c,d) western Irish Sea (WIS) grounds

Densities of Stage I $\left(0.11 \pm 0.09\right.$ ind. $\left.\mathrm{m}^{-3}\right)$ and II $\left(0.01 \pm 0.02\right.$ ind $\left.\mathrm{m}^{-3}\right)$ larvae were also significantly different in the WIS (Wilcoxon signed rank test, $\mathrm{n}_{1}=$ $\left.\mathrm{n}_{2}=24, Z=-4.1, \mathrm{p}<0.001\right)$. Highest densities of Stage I larvae in the WIS were observed at the southern and central parts of the ground, with stations on the southeast boundary either lacking larvae or containing very low densities (Fig. 2c). Several stations on the southeastern boundary were lacking Stage II larvae, and highest densities of this stage were observed to the south (Fig. 2d). Densities of Stage I larvae between the WIS and Aran grounds were similar (Mann-Whitney $U$-test, $\mathrm{n}_{1}=\mathrm{n}_{2}=24, U=$ $239, \mathrm{p}=0.31$ ). However, significantly lower densities of Stage II larvae were observed in the WIS compared to the Aran grounds, indicating later seasonality in the WIS (Mann-Whitney $U$-test, $\mathrm{n}_{1}=\mathrm{n}_{2}=24$, $U=134, \mathrm{p}<0.01)$.

\subsection{Drivers of vertical distribution (Aran and WIS grounds)}

The optimal (i.e. using AIC) multiple linear regression model explaining larval Stage I $N$. norvegicus WMD contained the following predictor variables: $\Delta$ Temperature, average zooplankton biomass, PEA and tidal height (Table 1). The optimal model explained $68 \%$ of the variance in larval WMD, with $\Delta$ Temperature contributing $40 \%$ and average zooplankton biomass contributing $22 \%$, followed by PEA $(5 \%)$ and finally tidal height (1\%; Table 2$)$. Model performance was evaluated using leave-oneout cross-validation; a correlation of observed and predicted values indicated good predictive performance (Spearman's rank correlation $=0.78, \mathrm{p}<0.001$ ).

There was a highly significant association between $\Delta$ Temperature and Stage I larval WMD. Lar- 
Table 1. Multiple linear regression model selection process. Response variable: weighted mean depth (WMD) of Stage I Nephrops norvegicus larvae. Predictor variables: $\Delta$ Temp (temperature at the surface - temperature at $60 \mathrm{~m}$ ), average zooplankton biomass (across 5 depth strata), potential energy anomaly (PEA), tidal height, bottom depth, N. norvegicus grounds, light (irradiance at $15 \mathrm{~m}$ ), depth of fluorescence maximum, time of day and WMD of zooplankton biomass. Model 4 (in bold) was selected as the optimal model based on Akaike's information criterion (AIC). $\triangle$ AIC indicates the change in AIC observed in competing models relative to the optimal model

\begin{tabular}{|c|c|c|c|}
\hline Model no. & Structure & AIC & $\Delta \mathrm{AIC}$ \\
\hline 1 & $\mathrm{WMD} \sim \Delta \mathrm{Temp}$ & 275.4 & 9.6 \\
\hline 2 & WMD $\Delta$ Temp + Average Biomass & 271.7 & 5.9 \\
\hline 3 & WMD $\Delta$ Temp + Average Biomass + PEA & 266.6 & 0.8 \\
\hline 4 & WMD $\sim \Delta$ Temp + Average Biomass + PEA + Tide & 265.8 & $\mathbf{0 . 0}$ \\
\hline 5 & WMD $\sim \Delta$ Temp + Average Biomass + PEA + Tide + Depth & 266.7 & 0.9 \\
\hline 6 & WMD $\sim \Delta$ Temp + Average Biomass + PEA + Tide + Ground & 267.1 & 1.3 \\
\hline 7 & WMD $\sim \Delta$ Temp + Average Biomass + PEA + Tide + Light & 267.3 & 1.5 \\
\hline 8 & WMD $\sim \Delta$ Temp + Average Biomass + PEA + Tide + Fluorescence Depth Max. & 267.7 & 1.9 \\
\hline 9 & WMD $\sim \Delta$ Temp + Average Biomass + PEA + Tide + Time of Day & 267.7 & 1.9 \\
\hline 10 & WMD $\sim \Delta$ Temp + Average Biomass + PEA + Tide + Biomass WMD & 267.7 & 1.9 \\
\hline
\end{tabular}

Table 2. Multiple linear regression for weighted mean depth (WMD) of Stage I Nephrops norvegicus larvae. Predictor variables retained in optimal model: $\Delta$ Temp (temperature at the surface - temperature at $60 \mathrm{~m}$ ), average zooplankton biomass (across 5 depth strata), potential energy anomaly (PEA) and tidal height, AIC: Akaike's information criterion; $\mathrm{n}=41$

\begin{tabular}{|lrrrrc|}
\hline Term & Estimate & SE & $t$-value & $\mathrm{p}$-value & $\mathrm{r}^{2}$ \\
\hline Intercept & 13.64 & 3.43 & 3.98 & $<0.001$ \\
Temp & -26.31 & 4.47 & -5.89 & $<0.001$ & 0.40 \\
Average biomass & 60.28 & 17.63 & 3.42 & $<0.01$ & 0.22 \\
PEA & -0.17 & 0.07 & -2.55 & $<0.05$ & 0.05 \\
Tide & 1.25 & 0.78 & 1.61 & 0.12 & 0.01 \\
AIC $=265.8$ & & \multicolumn{5}{c}{ Overall $\mathrm{r}^{2}=0.68$} \\
\hline
\end{tabular}

val WMD appeared shallower when a warmer surface layer was present, but WMD was deeper when water was warmer at depth (Table 2; Fig. 3a). The significance of this factor was identified due to strong oceanographic differences among stations. When a cooler and fresher surface layer was present, as observed at stations on the Aran grounds, larvae were deeper in the water column (Fig. 4). However, when temperature was constant through the water column or a warmer surface layer was present, as was seen on the WIS grounds, larvae resided closer to the surface (Fig. 4).

A significant relationship was observed between average zooplankton biomass (across 5 depth strata) and Stage I larval WMD (Table 2; Fig. 3b). Higher zooplankton biomass resulted in larvae inhabiting deeper parts of the water column (Fig. 5). By contrast, in the presence of low biomass, larvae appeared closer to the surface. The PEA, an indicator of stratification, explained only $5 \%$ variation in WMD, with
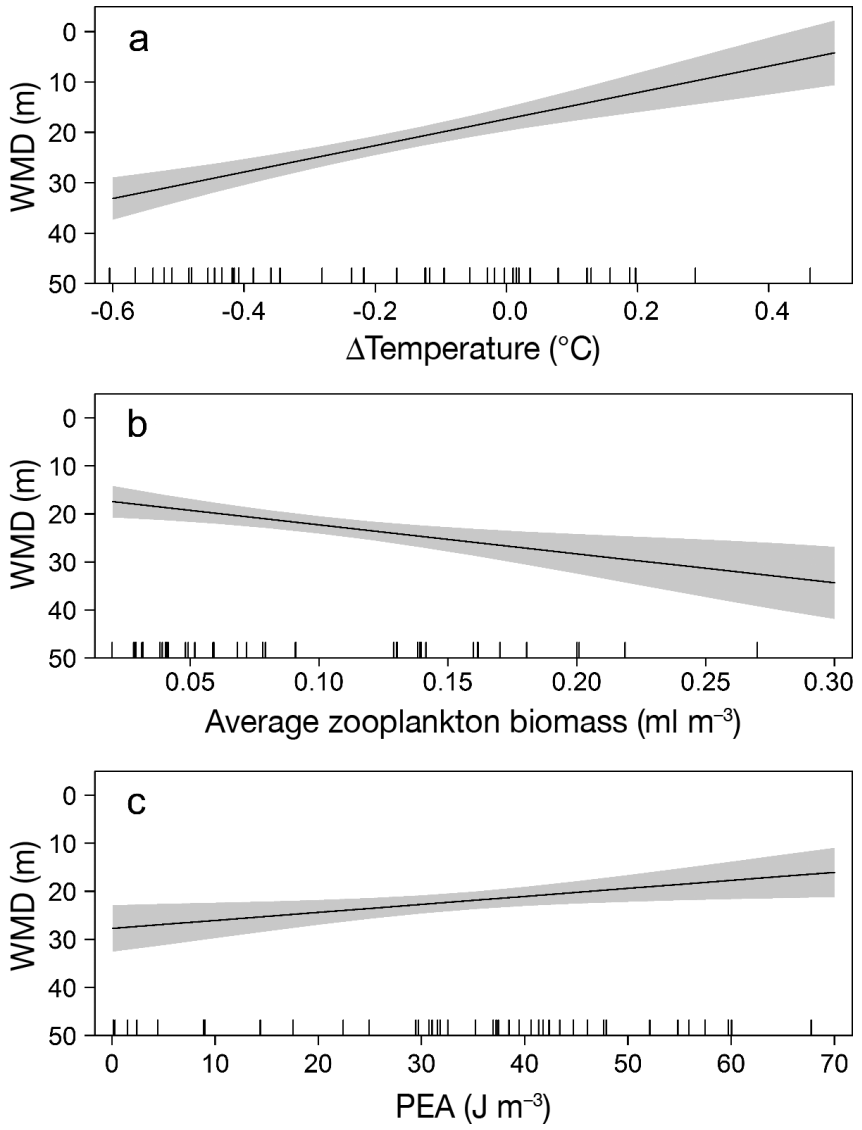

Fig. 3. Association between weighted mean depth (WMD) of Stage I Nephrops norvegicus larvae and (a) $\Delta$ Temperature (between surface and $60 \mathrm{~m}$; negative values on $x$-axis indicate a cooler surface layer, and positive values represent a warmer surface layer), (b) average zooplankton biomass (across 5 depth strata) and (c) potential energy anomaly (PEA). Lines and shaded areas indicate significant relationships and 95\% CIs from multiple regression analysis. Ticks along $X$-axis indicate field observations for the predictor variable 


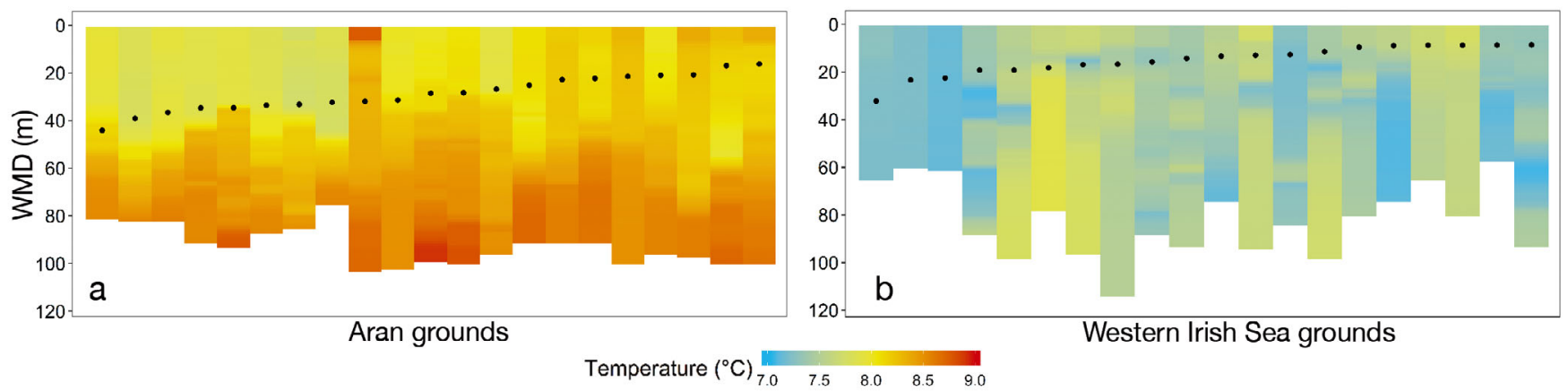

Fig. 4. Weighted mean depth (WMD) of Stage I Nephrops norvegicus larvae (black points), sorted from deepest to shallowest, overlaid on the vertical temperature profile on the (a) Aran grounds and (b) western Irish Sea grounds. For each station, the end of the data on the $y$-axis indicates bottom depth. Only stations with $>10$ larvae are included
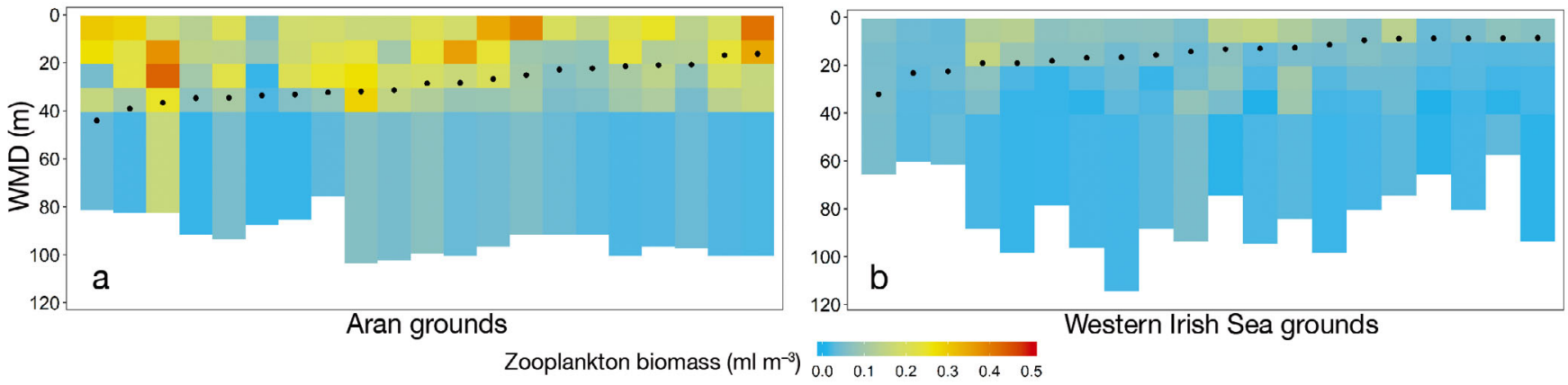

Fig. 5. Weighted mean depth (WMD) of Stage I Nephrops norvegicus larvae (black points), sorted from deepest to shallowest, overlaid on zooplankton biomass at each sampled stratum on the (a) Aran grounds and (b) western Irish Sea grounds. For each station, the end of the data on the $y$-axis indicates bottom depth. Only stations with $>10$ larvae are included

larvae observed closer to the surface when the water column was more stratified and deeper when it was less stratified (Fig. 3c). PEA was lowest to the western and northern areas of the Aran grounds and to the eastern boundary of the WIS grounds. Bottom depth was 85 to $115 \mathrm{~m}$ for stations on the Aran grounds and 68 to $109 \mathrm{~m}$ on the WIS grounds.

\subsection{Vertical migration of larvae (fixed station)}

Fixed station sampling occurred over 3 consecutive days in the WIS, beginning at 21:00 $\mathrm{h}$, and samples were collected every $3 \mathrm{~h}$ thereafter until 18:00 $\mathrm{h}$ on the third day, resulting in 24 sampling events. Bottom depth at the fixed station was $99 \mathrm{~m}$. The vast majority of larvae $(94 \%)$ resided within the upper $30 \mathrm{~m}$ of the water column, with the highest proportion (45\%) observed between 10 and $20 \mathrm{~m}$. Larvae were absent from the deepest stratum $(>40 \mathrm{~m})$ for $50 \%$ of sampling events. Stage I larvae were present for each sampling event, with average densities of $0.08 \pm$ 0.03 ind. $\mathrm{m}^{-3}$ (mean $\pm \mathrm{SD}$ ). Larval densities did not vary significantly from day to night (Mann-Whitney
$U$-test, $\left.\mathrm{n}_{1}=\mathrm{n}_{2}=9, U=27, \mathrm{p}=0.26\right)$, indicating that catchability remained consistent over the diel cycle. Average Stage I WMD across all 3 diel cycles was $15.48 \pm 4.44 \mathrm{~m}$ (mean $\pm \mathrm{SD})$. Stage II larvae were present in very low numbers at the fixed station $\left(0.002 \pm 0.002\right.$ ind. $\left.\mathrm{m}^{-3}\right)$.

Larvae consistently ascended and descended through the water column over the diel cycle (Fig. 6). The sustained vertical movement of larvae was significantly influenced by time of day (ANOVA, $F_{7,16}=$ 4.7, $\mathrm{p}<0.01$; Fig. 6a). Larvae made a significant ascent prior to sunset between 15:30 and 18:30 h (Tukey's HSD, p < 0.05). A descent was observed between 18:30 and 00:30 h (Tukey's HSD, p = 0.06). A second ascent took place before sunrise between 00:30 and 06:30 h (Tukey's HSD, p < 0.05) before another descent after sunrise between 06:30 and 15:30 h (Tukey's HSD, $\mathrm{p}<0.05$ ). Larvae were deepest during the day at $12: 30 \mathrm{~h}(18.56 \pm 2.89 \mathrm{~m})$ and $15: 30 \mathrm{~h}$ $(20.29 \pm 4.29 \mathrm{~m})$ and during the night at $00: 30 \mathrm{~h}$ $(19.86 \pm 3.45 \mathrm{~m})$ (Fig. 6a). In contrast, they were shallowest at sunrise at 06:30 h $(10.72 \pm 3.44 \mathrm{~m})$, shortly prior to sunset at $18: 30 \mathrm{~h}(11.52 \pm 2.55 \mathrm{~m})$ and soon after sunset at $21: 30 \mathrm{~h}(12.82 \pm 2.47 \mathrm{~m})$. Related to 

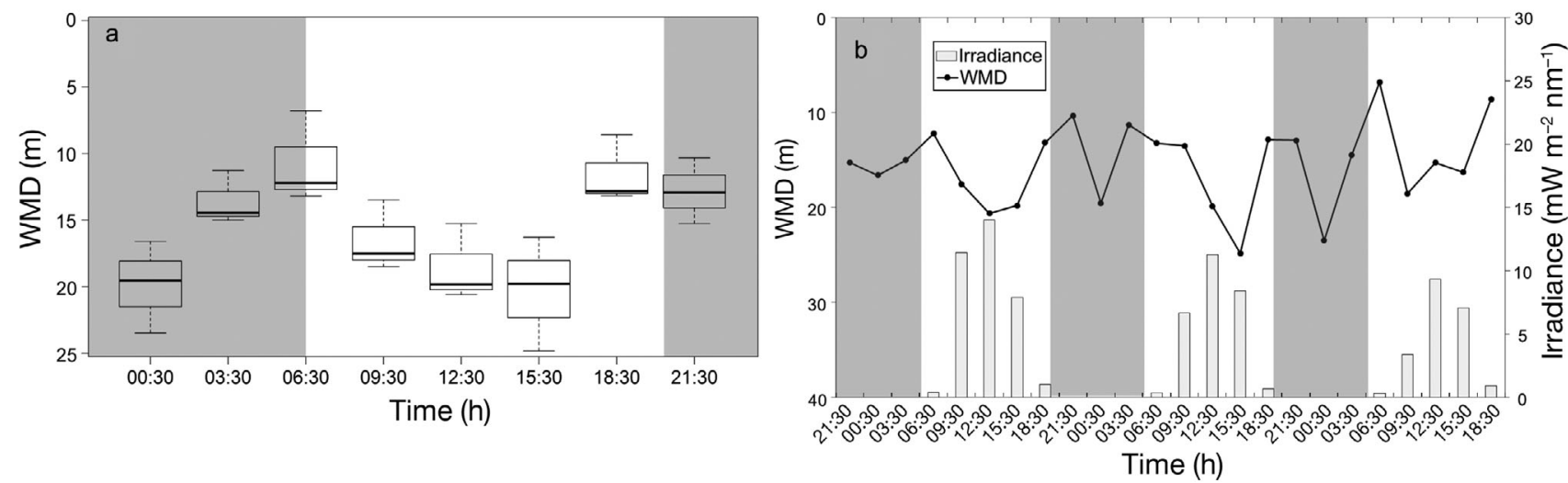

Fig. 6. Fixed station weighted mean depth (WMD) of Stage I Nephrops norvegicus larvae (a) averaged across $3 \mathrm{~d}$ for each sampled time and (b) at each individual sampling event with irradiance at $15 \mathrm{~m}$ indicated by light grey bars. Central lines in boxplots correspond to median depths, box extremities indicate 1st and 3rd quartiles and whiskers specify range. Times represent mid-haul, and shading indicates sunset to sunrise. Bottom depth at the fixed station was $99 \mathrm{~m}$

time of day, the WMD of larvae was also significantly influenced by light, expressed as downwelling irradiance at $15 \mathrm{~m}\left(\mathrm{n}=15, \mathrm{p}=0.002, \mathrm{r}^{2}=0.52\right)$. Larvae were often deepest when irradiance was high, such as at midday (Fig. 6b). The midnight descent and subsequent ascent were observed on each of the 3 nights; however, on the first night it was not as pronounced as on the second or third. What was consistent was the tendency for larval WMD to descend rapidly and return to the same depth again on either side of a midnight sink (this pattern is apparent by comparing near-identical depths at 21.30 and $03: 30 \mathrm{~h}$ on each of the 3 nights sampled; Fig. 6b).

\subsection{Implications of DVM for larval transport}

Particle retention was highest for the no DVM scenario and decreased when a twilight or nocturnal DVM was introduced. On the Aran grounds, retention was very low, with all 3 DVM scenarios resulting in $<1 \%$ larval retention (Table 3 ). The majority of particles originating from the Aran grounds were advected north and stayed close to the coast (Fig. 7). Advection distance was $181.5 \pm 102.8 \mathrm{~km}$ (mean \pm
SD) for no DVM, $181.2 \pm 98.9 \mathrm{~km}$ for twilight DVM and $199.5 \pm 106.4 \mathrm{~km}$ for nocturnal DVM. The maximum distance advected for all 3 DVM scenarios on the Aran grounds was $>580 \mathrm{~km}$.

Particle retention was greater on the WIS grounds (Table 3). Again, the no DVM scenario resulted in the highest retention $(32.3 \%)$ and an advection distance of $99.8 \pm 68.1 \mathrm{~km}$. Retention was reduced by more than half for the twilight $(15.1 \%)$ and nocturnal $(15.0 \%)$ DVM scenarios. Advection distances were $125.0 \pm 81.4 \mathrm{~km}$ for the twilight and $120.5 \pm 80.3 \mathrm{~km}$ for the nocturnal DVM behaviours. A large number of particles were either transported north or a small distance south after particle release from the WIS grounds (Fig. 7).

\section{DISCUSSION}

Larval seasonality is one critical element of recruitment success (James et al. 2003, Husebo et al. 2009), and this survey of Nephrops norvegicus larvae highlighted substantial differences in larval timing, even across grounds at the same latitude in Ireland. On the Aran grounds, off Ireland's west coast, a high propor-

Table 3. Particle retention (proportion of larvae retained on ground) and advection distance (average straight line distance between initial and final particle positions; \pm SD) for 3 diel vertical migration (DVM) behaviour scenarios on the Aran grounds and western Irish Sea (WIS) grounds obtained from particle-tracking simulations

\begin{tabular}{|c|c|c|c|c|c|c|}
\hline & \multicolumn{3}{|c|}{ - Aran grounds } & \multicolumn{3}{|c|}{ - WIS grounds- } \\
\hline & No DVM & Twilight DVM & Nocturnal DVM & No DVM & Twilight DVM & Nocturnal DVM \\
\hline Larval retention (\%) & 0.9 & 0.2 & 0.2 & 32.3 & 15.1 & 15.0 \\
\hline Advection distance $(\mathrm{km})$ & $181.5 \pm 102.8$ & $181.2 \pm 98.9$ & $199.5 \pm 106.4$ & $99.8 \pm 68.1$ & $125.0 \pm 81.4$ & $120.5 \pm 80.3$ \\
\hline
\end{tabular}




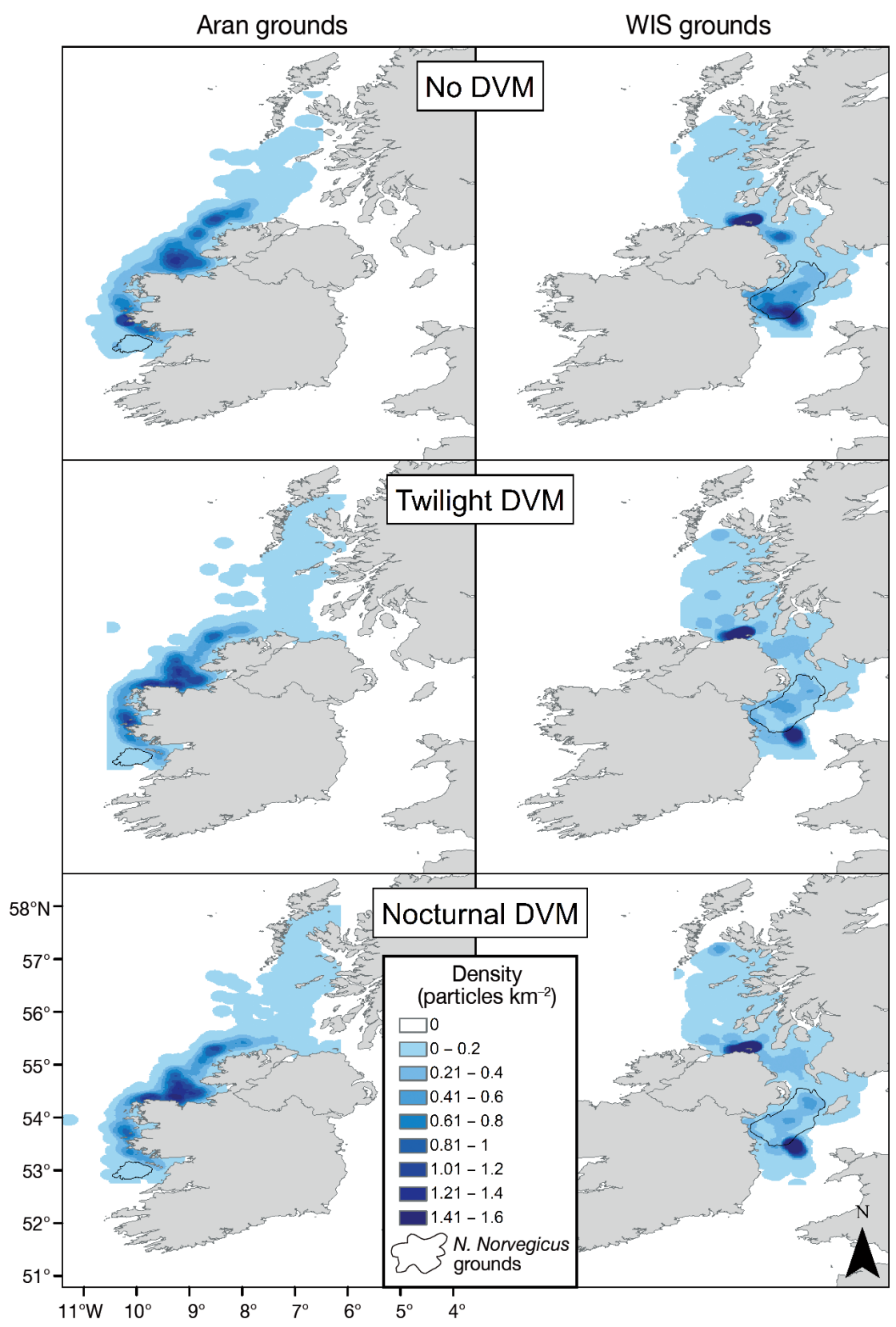

Fig. 7. Estimated particle distribution after a $60 \mathrm{~d}$ simulated dispersal based on regional oceanographic conditions for the relevant periods in 2018 in 3 diel vertical migration (DVM) scenarios (no DVM, twilight DVM and nocturnal DVM) for the Aran grounds and western Irish Sea (WIS) grounds. Beginning of simulation was set at 15 March for the Aran grounds and 1 April for the WIS grounds can be explained by a close relationship between temperature, spawning time and incubation duration (Farmer 1974, Sardà 1995). The variation in larval phenology between grounds was further demonstrated from opportunistic sampling on the Galway Bay grounds, where Stage III larvae were observed at each of the 3 stations, indicating that development was even further advanced in this coastal area off the west coast. Stage I larvae have previously been observed as early as February in Galway Bay, with each of the 3 stages being present in April (de Bhaldraithe 1976).

Sampling larvae from 2 distinct populations with differing oceanographic regimes on the Aran and WIS grounds allowed the drivers of vertical distribution to be identified. The principal driver of vertical distribution at these spatially separated stations was a temperature differential through the water column ( $\Delta$ Temperature), which was expressed as surface temperature minus temperature at $60 \mathrm{~m}$ (note that this value changes sign, depending on whether it is warmer at the surface or at depth). In the WIS, the water column was mostly homogeneous with a slightly warmer surface layer at several stations. Meanwhile, many stations on the Aran grounds displayed a fresh, cooler surface layer above a warmer, more saline bottom layer. Larvae were associated with warmer water; where warmer water was found at depth (i.e. Aran grounds), larvae were deeper, and where warmer water was at the surface (i.e. WIS grounds), larvae were found shallower (Fig. 4). The cool, fresh surface layer on the Aran grounds likely originated from the River Shannon, Ireland's largest river, to the

tion of Stage II larvae indicated that the larval season has been underway for some time by the start of April 2018. Stage I larvae were still present in higher densities than Stage II at the Aran grounds, which is likely due to mortality between larval stages (Nichols et al. 1987). On the cooler WIS grounds (east coast), the larval season was less advanced with much lower densities of Stage II larvae. The contrast in timing south. Huang et al. (1993) described the River Shancoastal water in temperature and salinity as it travels north towards the Aran grounds. Compared to coastal waters, the plume is cooler in spring and warmer in summer with maximum temperature differences of $1.5^{\circ} \mathrm{C}$. River discharge influences its size, and wind affects the direction of the plume (Huang et non plume as being different from the surrounding 
al. 1993). Overall, these results suggest a preference for warmer water, which is a fundamental factor in $N$. norvegicus larval development rates (Thompson \& Ayers 1989, Dickey-Collas et al. 1996).

Higher zooplankton biomass resulted in a deeper WMD of Stage I larvae (Fig. 3b). Higher densities of zooplankton biomass were observed on the Aran grounds compared to the WIS, reflecting the earlier timing of the spring bloom in the area. The observed tendency to inhabit shallower water when biomass was low may be related to food availability. With insufficient food, larvae may forego the relative safety of deeper water, where protection against visualbased predators is enhanced, to spend longer feeding near the surface, where food availability is better. In contrast, when the availability of food is adequate, larvae may occupy deeper water to avoid predation. $N$. norvegicus larvae consume more prey when food levels are high and will feed for longer if previously starved (Pochelon et al. 2009). Our results suggest that $N$. norvegicus larvae adapt their behaviour as a plastic response to match food availability in their environment. This adaptive response could be of benefit both to larvae hatched before the spring bloom which may be exposed to inadequate feeding conditions and to those hatched after the bloom with more plentiful food. Indeed, larvae in the WIS were previously observed closer to the surface during the early stages of the spring bloom in April and were deeper later in the season when chl a levels were higher (Lindley et al. 1994). Behavioural changes in response to feeding were also observed in the isopod Eurydice pulchra and estuarine crab Rhithropanopeus harrisi, whose response to light changes with satiation level (Jones \& Naylor 1970, Cronin \& Forward 1980).

PEA was used as an index of stratification in the study. The results indicated that larvae were shallower when PEA was high; however, its relative importance was small. PEA increases over the course of the larval season due to surface heating (Simpson et al. 1977). The WIS gyre, which begins to appear in spring with the onset of thermal stratification, has been suggested to aid $N$. norvegicus' larval retention (Hill et al. 1996, Horsburgh et al. 2000, Olbert et al. 2011). Gyral currents are restricted to the upper layers of the water column; therefore, larvae in surface waters would be more likely to benefit from the retentive properties of the gyre (Horsburgh et al. 2000). However, in the absence of a known gyre, such as on the Aran grounds, increased current velocities at the surface may lead to a higher probability of transport away from the ground (Fernand et al. 2006, O'Sullivan et al. 2015). A characteristic feature of a highly stratified water column is a thermocline. The cruise took place early in the larval season, when the water column was predominantly mixed. However, in the months that followed, surface heating could be expected to cause greater stratification and, therefore, a steeper thermocline. The current study did not sample later in the season, and the potential influence of more intense stratification and a stronger thermocline was not examined. However, our results from earlier in the season suggest that stratification was associated with larvae appearing closer to the surface. Observation when stratification is more intense is needed to further explore this relationship.

Fixed station sampling over the diel cycle revealed a short-distance twilight DVM through the water column. Stage I larvae ascended the water column twice daily, prior to both sunrise and sunset, followed by a daytime descent and a rapid sink at midnight. Recall that no significant relationship was observed between larval WMD and time of day at horizontally sampled stations. This can be explained because at the fixed station, temperature, average zooplankton biomass and PEA remained relatively constant, making it possible to identify the DVM behaviour. However, when greater variation existed in environmental factors between stations, the influence of time of day was not significant (noting also that different times of day within stations were not sampled). It may be that the factors that are significant in horizontal patterns $(\Delta$ Temperature, zooplankton biomass and PEA) govern the vertical distribution from which a DVM is performed.

Larvae of $N$. norvegicus have previously been documented moving closer to the surface at dusk (Hillis 1974, Lindley et al. 1994). But Hillis (1974) also reported a vertical dispersion of larvae at night with increased numbers of larvae appearing deeper in the water column, which may be equivalent to the midnight sink identified in the current study. Anaesthetised Stage I larvae passively sink at a rate of $9 \mathrm{~mm}$ $\mathrm{s}^{-1}$ (i.e. $32 \mathrm{~m} \mathrm{~h}^{-1}$ ) (Smith 1987). This sinking rate suggests that to descend at the speed observed in the present study, larvae must either sink at a rate that is slowed by active swimming or swim downwards and subsequently stop and maintain their position in the water column.

The midnight sink is a characteristic behaviour in twilight migrators where organisms descend at midnight after the dusk ascent (Cushing 1951). The behaviour has been attributed to satiation, i.e. organisms ascend to the surface to feed and descend at midnight after becoming satiated before a second ascent (Pearre 1973, Simard et al. 1985). Another ex- 
planation is the avoidance of vertically migrating predators, which is thought to cause the midnight sink in Calanus (avoiding krill) (Tarling et al. 2002). Although the vertical migration observed in $N$. norvegicus larvae was relatively short, only $\sim 10 \mathrm{~m}$, it is proportionately significant considering $94 \%$ of larvae resided within the upper $30 \mathrm{~m}$ at the fixed station. A vertical migration of this magnitude may be advantageous by increasing exposure to warmer surface waters, leading to faster development, and reducing risks associated with prolonged time in the vulnerable larval phase (Neverman \& Wurtsbaugh 1994). Avoiding a long-distance DVM that involves moving to cooler depths may also reduce an associated delay in development.

The vertical migration observed in $N$. norvegicus was closely related to sunrise and sunset, making light, specifically the rapidly changing light levels associated with dawn and dusk, a likely causal factor (Fig. 6). Sampling was carried out in mid-April, when sunrise and sunset times in the Irish Sea were approximately 06:30 and 20:20 h, respectively. Interestingly, light was also implicated in the observations of a dusk ascent by Hillis (1974), whose observations were in June, when sunset would have occurred at least an hour later. N. norvegicus adults on the continental shelf also display a crepuscular burrow emergence pattern related to light, with peak emergence at dawn and dusk (Aguzzi et al. 2003). These observations suggest that rapidly changing light levels are an important cue governing the behaviour of $N$. norvegicus throughout the life cycle.

Finally, particle-tracking model simulations of oceanographic conditions in 2018 indicated that the presence of DVM behaviour reduces larval retention. Little difference in retention was observed between the twilight and nocturnal DVM scenarios, but retention was markedly lower in both cases than it was for the no DVM scenario. In the WIS, by remaining fixed at $20 \mathrm{~m}$, close to peak gyral flow, larvae may be more likely to become entrained in the gyre and experience its retentive benefits. The upward vertical migrations employed on the WIS grounds would have decreased exposure to peak gyral flow, and fastflowing near-surface currents may increase advection away from natal habitat. The presence of a vertical migration has similarly been shown to have a large influence on the transport patterns of European anchovy (Ospina-Alvarez et al. 2012), Northeast Arctic cod (Vikebø et al. 2007) and bicolor damselfish (Paris \& Cowen 2004), making it a vital consideration when estimating larval dispersal extent and pathways. Through empirical sampling, the present study has demonstrated that $N$. norvegicus larvae do indeed perform a DVM, and larval retention-enhancing mechanisms such as the WIS gyre can only partially benefit the retention of larvae since DVM takes them away from optimal gyral flows for part of the $24 \mathrm{~h}$ cycle. Phelps et al. (2015) similarly observed lower retention (and greater advection distance) in the WIS when including a DVM component. The results indicate that the observed DVM behaviour in $N$. norvegicus larvae does not improve the likelihood of retention and is, in fact, less favourable for retention on the 2 grounds tested in the current study.

No gyral retention mechanism has been documented for the Aran grounds, so it is interesting that predicted particle retention rates on the Aran grounds were extremely low $(<1 \%)$ in each of the DVM scenarios for 2018. At the end of the simulation, many of the particles had been transported to the northwest coast of Ireland and even further north to Scotland (Fig. 7). Survival of $N$. norvegicus is dependent on larvae settling on suitable mud habitat. Therefore, local oceanographic processes provide an important control on recruitment. The fact that all simulations at the Aran grounds resulted in extremely low retention is of significance because of historic fluctuations in adult stock sizes at these grounds (Doyle et al. 2018b). Poor larval retention from unfavourable oceanographic conditions may be a contributing factor, especially as this population may receive few larval donations from other large grounds (O'Sullivan et al. 2015). O'Sullivan et al. (2015) observed substantially higher larval retention rates of $15.8 \%$ for 2011 and $14.4 \%$ for 2012 compared to the present study's observations for 2018 (note: in previous simulations, no DVM was specified, and particles had a later release and a shorter pelagic duration). However, the vast differences in retention across years suggest that this population may be subject to significant interannual variability in ocean-driven dispersal. Indeed, interannual variability in ocean currents may be more important for retention than other factors such as vertical behaviour (Dickey-Collas et al. 2009, Kvile et al. 2018). This association has obvious implications for fisheries management because variable interannual oceanography and a low rate of larval donation from other grounds may be key factors in the decline and fluctuation of stock abundance on the Aran grounds or other fishing grounds with similar characteristics. Release date is also an important consideration, as larvae released later in the season would be expected to have a shorter larval duration due to warmer sea temperatures. Thus, the date of larval release is important in dictating the length of time that larvae 
spend exposed to local oceanographic conditions, hence their dispersal and likelihood of retention. In the current study, particles were released in midMarch to reflect the larval stages observed in empirical sampling, but it would also be interesting to examine the consequences for dispersal of different release times. An extended time series of larval retention estimates which evaluates the role of oceanographic variability and release timing for recruitment would be valuable on grounds which have undergone stock fluctuations in the past.

\section{CONCLUSIONS}

The present study showed the vertical distribution of Nephrops norvegicus larvae was influenced by differential temperature in the water column, average zooplankton biomass and, to a lesser extent, PEA. The findings suggest a complex vertical distribution in $N$. norvegicus that balances the benefits of accelerated development with food availability and potentially predator evasion. Larvae performed a DVM, characterised by a twilight vertical migration with a midnight sink. Particle-tracking results indicated that the observed DVM decreases larval retention and the retentive properties of the WIS gyre are lower than previously suggested, due to larvae migrating outside the zone of peak gyral flow for a proportion of the $24 \mathrm{~h}$ period. The results may be applied in particle-tracking studies to estimate larval transport in N. norvegicus, to help predict impacts of low larval retention for fisheries stock fluctuations as well as impacts from climate-driven changes to oceanography (e.g. Cetina-Heredia et al. 2015).

Acknowledgements. This project (Grant-Aid Agreement No. CF/16/04) and research survey (CV18012) were accomplished with the support of the Marine Institute and funded under the Marine Research Sub-Programme by the Irish Government. Special thanks to Leigh Barnwall, Darragh Furey, Catherine Jordan, Eoin MacLaughlin and Sophia Wassermann for sample collection; Sarah Ayres and EllieAnn Conneely for processing of samples; and Kieran Lyons for providing ROMS model output for particle tracking. We are also grateful to the RV 'Celtic Voyager' crew and Marine Institute Research Vessel Operations, especially Aodhan Fitzgerald and Rosemarie Butler, for support and assistance throughout the research survey.

\section{LITERATURE CITED}

Aguzzi J, Sardà F, Abelló P, Company JB, Rotllant G (2003) Diel and seasonal patterns of Nephrops norvegicus (Decapoda: Nephropidae) catchability in the western Mediterranean. Mar Ecol Prog Ser 258:201-211
Akaike H (1974) A new look at the statistical model identification. IEEE Trans Automat Contr 19:716-723

* Batchelder HP, Edwards CA, Powell TM (2002) Individualbased models of copepod populations in coastal upwelling regions: implications of physiologically and environmentally influenced diel vertical migration on demographic success and nearshore retention. Prog Oceanogr 53: 307-333

Beers JR (1976) Determination of zooplankton biomass. In: Steedman HF (ed) Zooplankton fixation and preservation. UNESCO Press, Paris, p 35-84

Bell MC, Redant F, Tuck I (2006) Nephrops species. In: Phillips BF (ed) Lobster: biology, management, aquaculture and fisheries. Blackwell, Oxford, p 412-461

Bollens SM, Frost BW (1989) Predator-induced diel vertical migration in a planktonic copepod. J Plankton Res 11: 1047-1065

Cetina Heredia P, Roughan M, van Sebille E, Feng M, Coleman MA (2015) Strengthened currents override the effect of warming on lobster larval dispersal and survival. Glob Change Biol 21:4377-4386

Clements A, Butler R, Doyle J, Ourens R and others (2018) Western Irish Sea Nephrops grounds (FU15) 2018 UWTV survey report and catch options for 2019. AFBI and Marine Institute UWTV survey report. Marine Institute, Galway

C Cronin W, Forward B (1980) The effects of starvation on phototaxis and swimming of larvae of the crab Rhithropanopeus harrisi. Biol Bull 158:283-294

Cushing DH (1951) The vertical migration of planktonic crustacea. Biol Rev Camb Philos Soc 26:158-192

* Dabrowski T, Lyons K, Cusack C, Casal G, Berry A, Nolan GD (2016) Ocean modelling for aquaculture and fisheries in Irish waters. Ocean Sci 12:101-116

* de Bhaldraithe P (1976) Larvae of the Dublin Bay prawn Nephrops norvegicus (L.) in Galway Bay, Ireland. Estuar Coast Mar Sci 4:225-229

* Dickey-Collas M, Gowen RJ, Fox CJ (1996) Distribution of larval and juvenile fish in the western Irish Sea: relationship to phytoplankton, zooplankton biomass and recurrent physical features. Mar Freshw Res 47:169-181

* Dickey-Collas M, McQuaid N, Armstrong MJ, Allen M, Briggs RP (2000) Temperature-dependent stage durations of Irish Sea Nephrops larvae. J Plankton Res 22:749-760

* Dickey-Collas M, Bolle LJ, van Beek JKL, Erftemeijer PLA (2009) Variability in transport of fish eggs and larvae. II. Effects of hydrodynamics on the transport of Downs herring larvae. Mar Ecol Prog Ser 390:183-194

* dos Santos A, Santos AMP, Conway DVP, Bartilotti C, Lourenço P, Queiroga H (2008) Diel vertical migration of decapod larvae in the Portuguese coastal upwelling ecosystem: implications for offshore transport. Mar Ecol Prog Ser 359:171-183

Doyle J, O'Brien S, Ryan G, Galligan S and others (2018a) Porcupine Bank Nephrops grounds (FU16) 2018 UWTV survey report and catch scenarios for 2019. Marine Institute UWTV survey report. Marine Institute, Galway

Doyle J, O'Brien S, Ryan G, Galligan S and others (2018b) Aran, Galway Bay and Slyne Head Nephrops grounds (FU17) 2018 UWTV survey report and catch options for 2019. Marine Institute UWTV survey report. Marine Institute, Galway

Efron B (1983) Estimating the error rate of a prediction rule: improvement on cross-validation. J Am Stat Assoc 78: 316-331

Eiriksson H (1970) On the breeding cycle and fecundity of the 
Norway lobster at south-west Iceland. ICES CM 1970/K:6

Emsley SM, Tarling GA, Burrows MT (2005) The effect of vertical migration on retention in the Irish Sea. Fish Oceanogr 14:161-174

Ennis GP (1975) Behavioral responses to changes in hydrostatic pressure and light during larval development of the lobster Homarus americanus. J Fish Res Board Can 32:271-281

Ennis GP (1986) Swimming ability of larval American lobsters, Homarus americanus, in flowing water. Can J Fish Aquat Sci 43:2177-2183

Farmer ASD (1974) Reproduction in Nephrops norvegicus (Decapoda: Nephropidae). J Zool 174:161-183

Fernand L, Nolan GD, Raine R, Chambers CE, Dye SR, White M, Brown J (2006) The Irish coastal current: a seasonal jet-like circulation. Cont Shelf Res 26:1775-1793

Forward RB (1987) Comparative study of crustacean larval photoresponses. Mar Biol 94:589-595

Forward RB (1988) Diel vertical migration: zooplankton photobiology and behaviour. Oceanogr Mar Biol Annu Rev 26:361-393

* Grömping U (2006) Relative importance for linear regression in R: the package relaimpo. J Stat Softw 17:1-27

Hays GC (2003) A review of the adaptive significance and ecosystem consequences of zooplankton diel vertical migrations. Hydrobiologia 503:163-170

Hill AE, Brown J, Fernand L (1996) The western Irish Sea gyre: a retention system for Norway lobster (Nephrops norvegicus)? Oceanol Acta 19:357-368

Hillis JP (1974) Field observations on larvae of the Dublin Bay prawn Nephrops norvegicus (L.) in the western Irish Sea. Ir Fish Investig B 13:1-24

*Horsburgh KJ, Hill AE, Brown J, Fernand L, Garvine RW, Angelico MMP (2000) Seasonal evolution of the cold pool gyre in the western Irish Sea. Prog Oceanogr 46:1-58

Huang WG, Cracknell AP, Vaughan RA (1993) Satellite thermal observations of the River Shannon plume. Estuar Coast Shelf Sci 36:207-219

Huebert KB, Cowen RK, Sponaugle S (2011) Vertical migrations of reef fish larvae in the Straits of Florida and effects on larval transport. Limnol Oceanogr 56:1653-1666

*Hughes DA (1972) On the endogenous control of tideassociated displacements of pink shrimp, Penaeus duorarum Burkenroad. Biol Bull 142:271-280

Huntley M, Brooks ER (1982) Effects of age and food availability on diel vertical migration of Calanus pacificus. Mar Biol 71:23-31

Husebo A, Fossum P, Folkvord A, Vikebo F and others (2009) Effects of hatching time on year-class strength in Norwegian spring-spawning herring (Clupea harengus). ICES J Mar Sci 66:1710-1717

Jain AK, Dubes RC, Chen CC (1987) Bootstrap techniques for error estimation. IEEE Trans Pattern Anal Mach Intell 9:628-633

James A, Pitchford JW, Brindley J (2003) The relationship between plankton blooms, the hatching of fish larvae, and recruitment. Ecol Model 160:77-90

Johnson JW, LeBreton JM (2004) History and use of relative importance indices in organizational research. Organ Res Methods 7:238-257

Johnson MP, Lordan C, Power AM (2013) Habitat and ecology of Nephrops norvegicus. Adv Mar Biol 64:27-63

Jones DA, Naylor E (1970) The swimming rhythm of the sand beach isopod Eurydice pulchra. J Exp Mar Biol Ecol 4: 188-199
Kelly P, Sulkin SD, Van Heukelem WF (1982) A dispersal model for larvae of the deep sea red crab Geryon quinquedens based upon behavioral regulation of vertical migration in the hatching stage. Mar Biol 72:35-43

Kvile KØ, Romagnoni G, Dagestad KF, Langangen Ø, Kristiansen T (2018) Sensitivity of modelled North Sea cod larvae transport to vertical behaviour, ocean model resolution and interannual variation in ocean dynamics. ICES J Mar Sci 75:2413-2424

Lett C, Verley P, Mullon C, Parada C, Brochier T, Penven P, Blanke B (2008) A Lagrangian tool for modelling ichthyoplankton dynamics. Environ Model Softw 23:1210-1214

* Lindley JA, Williams R, Conway DVP (1994) Variability in dry weight and vertical distributions of decapod larvae in the Irish Sea and North Sea during the spring. Mar Biol 120:385-395

พ Marta-Almeida M, Dubert J, Peliz Á, Queiroga H (2006) Influence of vertical migration pattern on retention of crab larvae in a seasonal upwelling system. Mar Ecol Prog Ser 307:1-19

Marta-Almeida M, Dubert J, Peliz L, dos Santos A, Queiroga H (2008) A modelling study of Norway lobster (Nephrops norvegicus) larval dispersal in southern Portugal: predictions of larval wastage and self-recruitment in the Algarve stock. Can J Fish Aquat Sci 65:2253-2268

Neverman D, Wurtsbaugh WA (1994) The thermoregulatory function of diel vertical migration for a juvenile fish, Cottus extensus. Oecologia 98:247-256

Nichols JH, Bennett DB, Symonds DJ, Grainger R (1987) Estimation of the stock size of adult Nephrops norvegicus (L.) from larvae surveys in the western Irish Sea in 1982. J Nat Hist 21:1433-1450

\% O'Sullivan D, Lordan C, Doyle J, Berry A, Lyons K (2015) Metapopulation connectivity via larval transport of the Norway lobster Nephrops norvegicus in waters around Ireland: a modelled approach. Mar Ecol Prog Ser 534: 95-106

Olbert AI, Hartnett M, Dabrowski T, Mikolajewicz U (2011) Long-term inter-annual variability of a cyclonic gyre in the western Irish Sea. Cont Shelf Res 31:1343-1356

* Olbert AI, Dabrowski T, Nash S, Hartnett M (2012) Regional modelling of the 21st century climate changes in the Irish Sea. Cont Shelf Res 41:48-60

Ospina-Alvarez A, Parada C, Palomera I (2012) Vertical migration effects on the dispersion and recruitment of European anchovy larvae: from spawning to nursery areas. Ecol Model 231:65-79

* Paris C, Cowen R (2004) Direct evidence of a biophysical retention mechanism for coral reef fish larvae. Limnol Oceanogr 49:1964-1979

* Pearre S Jr (1973) Vertical migration and feeding in Sagitta elegans Verrill. Ecology 54:300-314

* Phelps JJC, Polton JA, Souza AJ, Robinson LA (2015) Behaviour influences larval dispersal in shelf sea gyres: Nephrops norvegicus in the Irish Sea. Mar Ecol Prog Ser 518:177-191

Pochelon PN, Calado R, dos Santos A, Queiroga H (2009) Feeding ability of early zoeal stages of the Norway lobster Nephrops norvegicus (L.). Biol Bull 216:335-343

Queiroga H, Blanton J (2005) Interactions between behaviour and physical forcing in the control of horizontal transport of decapod crustacean larvae. Adv Mar Biol 47:107-214

R Core Team (2018) R: a language and environment for statistical computing. R Foundation for Statistical Computing, Vienna 
Relini LO, Zamboni A, Fiorentino F, Massi D (1998) Reproductive patterns in Norway lobster (Nephrops norvegicus (L.), (Crustacea Decapoda Nephropidae) of different Mediterranean areas. Sci Mar 62:25-41

Roberts MH Jr (1971) Larval development of Pagurus longicarpus Say reared in the laboratory. III. Behavioral responses to salinity discontinuities. Biol Bull 140:489-501

Sardà F (1995) A review (1967-1990) of some aspects of the life history of Nephrops norvegicus. ICES Mar Sci Symp 199:78-88

Shanks AL (2009) Pelagic larval duration and dispersal distance revisited. Biol Bull 216:373-385

Shchepetkin AF, McWilliams JC (2005) The regional oceanic modeling system (ROMS): a split-explicit, free-surface, topography-following-coordinate oceanic model. Ocean Model 9:347-404

Simard Y, Lacroix G, Legendre L (1985) In situ twilight grazing rhythm during diel vertical migrations of a scattering layer of Calanus finmarchicus. Limnol Oceanogr 30: 598-606

Editorial responsibility: Marsh Youngbluth,

Fort Pierce, Florida, USA
Simpson JH, Hughes DG, Morris NCG (1977) The relation of seasonal stratification to tidal mixing on the continental shelf. In: Angel MV (ed) A voyage of discovery. Pergamon Press, Oxford, p 327-340

Smith RSM (1987) The biology of larval and juvenile Nephrops norvegicus (L.) in the Firth of Clyde. PhD thesis, University of Glasgow

Tarling GA, Jarvis T, Emsley SM, Matthews JBL (2002) Midnight sinking behaviour in Calanus finmarchicus: a response to satiation or krill predation? Mar Ecol Prog Ser 240:183-194

* Thompson BM, Ayers RA (1989) Laboratory studies on the development of Nephrops norvegicus larvae. J Mar Biol Assoc UK 69:795-801

Ungfors A, Bell E, Johnson ML, Cowing D, Dobson NC, Bublitz R, Sandell J (2013) Nephrops fisheries in European waters. Adv Mar Biol 64:247-314

Vikebø F, Jørgensen C, Kristiansen T, Fiksen Ø (2007) Drift, growth, and survival of larval Northeast Arctic cod with simple rules of behaviour. Mar Ecol Prog Ser 347:207-219

Submitted: May 20, 2019; Accepted: September 20, 2019 Proofs received from author(s): November 7, 2019 